\title{
STATISTICAL LITERACY IN UKRAINE: PROBLEMS AND DEVELOPMENTS
}

\author{
Osaulenko Oleksandr, Volodymyr Panteleiev, and Yakiv Karchev \\ The National Academy of Statistics, Accounting and Audit, Ukraine \\ bernstein@nasoa.edu.ua
}

This poster summarizes the current state of affairs in the Ukrainian system of statistical education and prospects for its development. Ukrainian higher educational institutions teaching economics have trained statistics throughout the study period - both within a general mathematical curriculum (probability theory, mathematical statistics, econometrics, etc.) and as part of vocational training for various economic specialties. Thanks to such features, statistical education is an integral part of training financiers, accountants, auditors, managers, etc.

Ukraine has made significant achievements in training specialists in statistics. Lately, ties between higher education institutions and main employers (official statistics and business) have been strengthened, including students' internships in the offices of employers, lectures by leading specialists, and more modern curricula such as ESTP and EMOS.

The center for contemporary statistical education of Ukraine is the National Academy of Statistics, Accounting and Audit, whose main mission is the training of highly qualified personnel, primarily for the needs of official statistics, in accordance with international recommendations and educational standards in this field. To implement the program "Learning throughout life", the Academy has developed training programs for continuous statistical education (retraining and second higher education), popularization of the profession, and a statistical literacy manual for general education schools. The Government of Ukraine has also initiated the creation of a International Statistical Institute for the countries of Eastern Europe, the Caucasus and Central Asia, on the basis of the Academy, as another training center. 